\title{
Cinética do Fósforo em Tecidos de Suínos em Crescimento1
}

\section{João Batista Lopes², Dorinha Miriam Silber S. Vitti ${ }^{3}$, Agustinho Valente de Figueirêdo², Hacy Pinto Barbosa ${ }^{4}$}

\begin{abstract}
RESUMO - Esta pesquisa foi realizada para estudar a cinética do fósforo $(\mathrm{P})$ em tecidos de suínos em crescimento, alimentados com rações contendo níveis crescentes de $\mathrm{P}$ total $(0,30 ; 0,40 ; 0,51 ; 0,65 ;$ e $0,73 \%)$, por meio do uso do ${ }^{32} \mathrm{P}$ como traçador. A taxa de retenção de ${ }^{32} \mathrm{P}$ e as atividades específicas relativa e padronizada no osso, fígado, coração, rim e músculo foram os indicadores da concentração de P inorgânico. Dez leitões híbridos comerciais, machos, castrados, com $20 \mathrm{~kg}$ PV, foram distribuídos em delineamento inteiramente casualizado, em esquema de parcela subdivida. Os leitões foram mantidos em gaiolas de metabolismo por um período de sete dias de adaptação e sete dias de coleta de amostras de sangue. No primeiro dia da fase de coleta, cada animal foi injetado, por via endovenosa, com 7,4 MBq ${ }^{32} \mathrm{P}$, como traçador. No $8^{\circ}$ dia, abateram-se os animais e coletaram-se amostras dos tecidos. Os valores médios da concentração de $\mathrm{P}$, da retenção de ${ }^{32} \mathrm{P}$ e da atividade específica relativa no osso, fígado, coração, rim e músculo foram, respectivamente, 65,79; 10,34; 8,39; 10,99; e $6,64 \mathrm{mg} / \mathrm{g}$ MS, 0,$0125 ; 0,0156 ; 0,0176 ; 0,0178$; e $0,0165 \%$ e 0,$6292 ; 0,6286 ; 0,5718 ; 0,5215$; e 0,6506 . Os níveis de P consumido não influenciaram a concentração de $\mathrm{P}$ no osso, fígado, coração, rim e músculo. A taxa de retenção de ${ }^{32} \mathrm{P}$ decresceu nos tecidos, na seguinte ordem: rim, coração, músculo, fígado e osso, independente da quantidade de P consumido. As trocas de $\mathrm{P}$ entre o plasma e os tecidos, osso, fígado e rim, cresceram com o aumento da ingestão de $\mathrm{P}$ da dieta.
\end{abstract}

Palavras-chave: Cinética, radiofósforo, suíno, diluição isotópica, ${ }^{32} \mathrm{P}$

\section{Phosphorus Kinetic in Tissue of Swine in the Growing Phase}

\begin{abstract}
This research was conducted to study the kinetic of phosphorus (P) in tissue of swine growing phase fed diets containing crescent levels of total phosphorus $(.30, .40, .51, .65 \mathrm{e} .73 \%)$, using ${ }^{32} \mathrm{P}$ as tracer. The rate of ${ }^{32} \mathrm{P}$ retention and the relative specific activity and standard in the bone, liver, heart, kidney and muscle were the markers of inorganic P concentration. Ten commercial crossbred barrows, with $20 \mathrm{~kg}$, were allotted to a completely randomized design in a split plot arrangement. The pigs were kept in metabolic cage for a seven-day period of adaptation and seven-day for blood samples collection. In the first day of the collection period, each animal was injected intravenously with $7.4 \mathrm{MBq}$ of ${ }^{32} \mathrm{P}$, as metabolic tracer. On $8^{\text {th }}$ day the animals were slaughtered and sample of tissues were collected. The mean values of the $\mathrm{P}$ concentration, of ${ }^{32} \mathrm{P}$ retention and of the relative specific activity in bone, liver, heart, kidney and muscle were $65.79,10.34,8.39,10.99$, and $6.64 \mathrm{mg} / \mathrm{g} \mathrm{DM} ; .0125, .0156, .0176, .0178$, and $.0165 \%$ and $.6292, .6286, .5718, .5215$, and .6506 , respectively. The levels of $\mathrm{P}$ intake did not affect the concentration of $\mathrm{P}$ in bones, liver heart, kidney and muscle. The ${ }^{32} \mathrm{P}$ retention in the tissues decreased in the following order: kidney, heart, muscles, liver and bone, independently of the amount of $\mathrm{P}$ intake. The P exchanges between the plasma and the tissues, bone, liver and kidney, increased with the increasing of the P intake from the diet.
\end{abstract}

Key Words: kinetic, radiophosphorus, swine, isotopic dilution, ${ }^{32} \mathrm{P}$

\section{Introdução}

As trocas bioquímicas do fósforo nos tecidos e fluidos animais são constantes e variam de intensidade em função da idade e do estádio fisiológico, principalmente, sendo importantes no diagnóstico da carência desse mineral, uma vez que níveis dietéticos insuficientes podem resultar em diminuição de sua concentração no organismo.

$\mathrm{O}$ uso de radioisótopos como o ${ }^{32} \mathrm{P}$ pode indicar a distribuição e as trocas entre tecidos e fluidos e quantificar a concentração desse mineral nos tecidos corporais, como resposta do seu metabolismo ao suprimento dietético. Isto pode ser obtido pela determinação da concentração de $\mathrm{P}$ e da taxa de retenção do ${ }^{32} \mathrm{P}$ e pelas atividades específicas relativa e padronizada nos órgãos e tecidos.

A escolha do tecido ou fluido para a avaliação da condição nutricional varia com o tipo de mineral em estudo. Sangue, urina, saliva e pêlos têm a vantagem de evitar o sacrifício do animal. Tecidos do corpo são mais complicados para serem obtidos com o animal

\footnotetext{
1 Pesquisa financiada pela FAPESP e parte da tese do primeiro autor.

2 Professores adjuntos do Departamento de Zootecnia do CCA-UFPI.

3 Professor do Centro de Energia Nuclear na Agricultura da USP.

${ }^{4}$ Pesquisador do Instituto de Zootecnia de Nova Odessa.
} 
vivo, mas as biópsias de fígado e de ossos da cauda são práticas promissoras no diagnóstico mineral (BELLAVER, sd).

O fósforo do plasma e dos fluidos extracelulares mantém intercâmbio com as células dos tecidos, que funcionam como compartimentos de acúmulo e doação deste mineral para os fluidos extracelulares, sendo a taxa metabólica determinada, além de outros fatores, pelo seu consumo. Parece então que as células dos tecidos estão sujeitas a mecanismo hormonal, que determina sua permeabilidade ao íon fosfato, fazendo com que, em caso de menor consumo, maior quantidade seja captada pelos fluidos extracelulares. Ocorre, também, aumento da mobilização do fósforo intracelular, que é perdido em maior quantidade, evidenciado pelo decréscimo no seu teor em alguns tecidos. A retenção do ${ }^{32} \mathrm{P}$, ao caracterizar a substituição do fósforo estável pelo radiotraçador, pode esclarecer a magnitude do intercâmbio do mineral no interior da célula com o plasma e os fluidos (BUENO, 1997).

A incorporação do fósforo nos vários tecidos e órgãos é variável e dependente da taxa de renovação e crescimento do tecido. A troca de fósforo nos tecidos decresce com a idade e aumenta, novamente, durante os períodos de atividade reprodutiva, sendo essas trocas mais intensas no fósforo lábil do esqueleto e na matéria esponjosa do osso (GEORGIEVSKII, 1982).

Assim, objetivou-se estudar a cinética do fósforo em tecidos de suínos em crescimento, alimentados com rações contendo níveis crescentes de fósforo total, por meio do uso do ${ }^{32} \mathrm{P}$ como traçador, tendo como indicadores a concentração de $\mathrm{P}$, a taxa de retenção de ${ }^{32} \mathrm{P}$ e as atividades específicas relativa e padronizada no osso, fígado, coração, rim e músculo.

\section{Material e Métodos}

A pesquisa foi desenvolvida no Laboratório de Nutrição Animal do Centro de Energia Nuclear na Agricultura da Universidade de São Paulo, utilizando-se dez leitões híbridos comerciais, machos, castrados, com peso de $20 \mathrm{~kg}$.

O delineamento experimental foi inteiramente casualizado, em esquema de parcela subdividida, em que os níveis de fósforo total $(\mathrm{Pt})$ da dieta (A: 0,30\% de $(\mathrm{Pt})$, provenientes dos ingredientes de origem vegetal, B: $0,40 \%$ de Pt; C: $0,51 \%$ de Pt; D: 0, $65 \%$ de $\mathrm{Pt}$; e E: $0,73 \% \mathrm{de} \mathrm{Pt}$ ), representaram as parcelas e os tipos de tecidos (osso, fígado, coração, rim e múscu- 1o), as subparcelas. O ajuste do fósforo total, nas dietas B, C, D e E, foi obtido pela adição de fosfato bicálcico. Foram usados análise de variância e teste de "t" para comparação das médias entre os tecidos e análise de regressão para as variáveis estudadas, dentro de cada tecido (SAS, 1986), relacionando os valores obtidos com os do fósforo consumido.

A comparação das dietas experimentais pode ser visualizada na Tabela 1.

Os leitões foram alojados em gaiolas metabólicas tipo PEKAS (1968), por um período de sete dias de adaptação e sete dias para coleta de amostras de sangue para determinação da atividade específica do ${ }^{32} \mathrm{P}$ no sangue. No primeiro dia da fase experimental, 7,4 Mbq de ${ }^{32} \mathrm{P}$, como fosfato de sódio $\left(\mathrm{Na}_{2} \mathrm{HPO}_{4}\right)$, livre de carregador, foram injetados em cada animal por via endovenosa. No oitavo dia, dois animais de cada nível de $\mathrm{P}$ dietético (parcela) foram sacrificados e amostras de osso (três últimas costelas), fígado, rim coração e músculo (longíssimus dorsi) foram retiradas, livres de material estranho.

Na determinação do P inorgânico do plasma e dos tecidos, seguiu-se o método descrito por FISKE e SUBBAROW (1925), e para a atividade do material radioativo, o efeito Cerenkov, em espectrômetro de cintilação líquida (IAEA, 1979; NASCIMENTO FILHO e LOBÃO, 1977). A análise bromatológica das dietas foi realizada de acordo com as recomendações da AOAC (1980). O teor de P nas dietas foi calculado pelo método vanadato-molibdato(SARRUGEe HAAG, 1974) e os cálculos das atividade específicas $\left({ }^{32} \mathrm{P} / \mathrm{P}\right.$ total) foram realizados conforme LOFGREEN (1960).

Nos tecidos, osso, fígado, coração, rim e músculo, foram calculadas a retenção de ${ }^{32} \mathrm{P}$ [(contagem por minuto (cpm) da amostra do tecido/g MS $\div$ dose total injetada)/(mg P/g MS)], a atividade específica padronizada [(cpm da amostra do tecido/g MS $\div \mathrm{mg} \mathrm{P/g} \mathrm{MS)/}$ (cpm dose injetada $\div \mathrm{kg}$ peso vivo)] e a atividade específica relativa (atividade específica da amostra do tecido/atividade específica da amostra do plasma).

\section{Resultados e Discussão}

Os valores da concentração de fósforo inorgânico no osso, fígado, coração, rim e músculo (Tabela 2) não foram influenciados pelos níveis de fósforo dietético.

Observou-se que as concentraçãos de fósforo no fígado, coração, rim e músculo foram semelhantes entre si. No entanto, o osso teve maior conteúdo deste mineral $(\mathrm{P}<0,01)$, o que está de acordo com as obser- 
Rev. bras. zootec.

Tabela 1- Composição das dietas experimentais

Table 1 - Composition of the experimental diet

\begin{tabular}{|c|c|c|c|c|c|}
\hline \multirow{2}{*}{ Ingrediente } & \multicolumn{5}{|c|}{$\begin{array}{l}\text { Nível de fósforo total (\%) } \\
\text { Level of total phosphorus }\end{array}$} \\
\hline & $\mathrm{A}$ & $\mathrm{B}$ & $\mathrm{C}$ & $\mathrm{D}$ & \\
\hline Ingredient & $(0,30)$ & $(0,40)$ & $(0,51)$ & $(0,65)$ & $(0,73)$ \\
\hline Milho (kg) & 84,80 & 83,46 & 82,17 & 81,86 & 82,14 \\
\hline \multicolumn{6}{|l|}{ Corn } \\
\hline \multicolumn{2}{|l|}{ Soybean meal } & 13,25 & 14,28 & 14,29 & 13,58 \\
\hline Óleo soja (kg) & 0,50 & 0,60 & 0,70 & 0,80 & 1,10 \\
\hline \multicolumn{6}{|l|}{ Soybean oil } \\
\hline \multicolumn{6}{|l|}{ Limestone } \\
\hline $\begin{array}{l}\text { P bicálcico }(\mathrm{kg})^{2} \\
\text { Dicalcium } P\end{array}$ & 0,00 & 0,52 & 1,05 & 1,75 & 2,18 \\
\hline $\begin{array}{l}\text { Sal (kg) } \\
\text { Salt }\end{array}$ & \multicolumn{5}{|c|}{ Salt } \\
\hline $\begin{array}{l}\text { Suplemento mineral }(\mathrm{kg})^{3} \\
\text { Mineral supplement }\end{array}$ & 0,10 & 0,10 & 0,10 & 0,10 & 0,10 \\
\hline $\begin{array}{l}\text { Suplemento vitamínico }(\mathrm{kg})^{3} \\
\text { Vitamin supplement }\end{array}$ & \multicolumn{4}{|c|}{ Vitamin supplement } & 0,40 \\
\hline \multicolumn{6}{|l|}{ Crude protein } \\
\hline \multicolumn{5}{|l|}{ Digestible energy } & 3415 \\
\hline \multicolumn{6}{|l|}{ Total $P$} \\
\hline Ca:P & 2,00 & 1,50 & 1,18 & 0,92 & 0,82 \\
\hline $\begin{array}{l}\mathrm{Ca}(\%)=32,3 . \\
2 \mathrm{Ca}(\%)=23,13 \%, \mathrm{P}(\%)=19,94 . \\
3 \text { Quantidade/kg de mistura (Amoun } \\
250 \mathrm{mg} ; \mathrm{Vit} \mathrm{B}_{2}, 750 \mathrm{mg} ; \text { Vit } \mathrm{B}_{6}, \\
3000 \mathrm{mg} ; \mathrm{Colina} \text { (Choline), } 3000 \mathrm{~m} \\
80.000 \mathrm{mg} ; \mathrm{Cu}, 12.000 \mathrm{mg} ; \mathrm{Mn}, 7 \\
4 \text { Com base em ROSTAGNO et al. } \\
{ }^{4} \text { From ROSTAGNO etal. (1987). }\end{array}$ & $\begin{array}{l}\text { A, } 1.75 \\
12,300 \\
125 c i m e n \\
100.000\end{array}$ & $\begin{array}{l}\text { Vit } \mathrm{D}_{3} \\
\text { liacina } \\
\text { promote } \\
00 \mathrm{mg} \\
0\end{array}$ & $\begin{array}{l}\text {; Vit E } \\
00 \mathrm{mg} \\
\text { g, Anti } \\
\text {. }\end{array}$ & $\begin{array}{l}\text { g; Vit K } \\
\text { totênico } \\
\text { Antioxiad }\end{array}$ & $\begin{array}{l}\text { g; Vit B } \\
\text { enic acid } \\
\text { O mg; Fe }\end{array}$ \\
\hline
\end{tabular}

Tabela 2 - Conteúdo de $\mathrm{P}$ nos tecidos em função dos níveis de $\mathrm{P}$ total da dieta Table 2 - $P$ content in tissue on the dietary total $P$ levels

\begin{tabular}{|c|c|c|c|c|c|c|}
\hline \multirow[t]{2}{*}{$\begin{array}{l}\text { Nível de } \mathrm{P} \text { total } \% \\
\text { Level of total } P\end{array}$} & \multirow[t]{2}{*}{$\begin{array}{c}\text { P consumido } \\
\text { P intake }\end{array}$} & \multicolumn{5}{|c|}{ Tipo de tecido } \\
\hline & & $\begin{array}{l}\text { Osso } \\
\text { Bone }\end{array}$ & $\begin{array}{l}\text { Fígado } \\
\text { Liver }\end{array}$ & $\begin{array}{c}\text { Coração } \\
\text { Heart }\end{array}$ & $\begin{array}{c}\text { Rim } \\
\text { Kidney }\end{array}$ & $\begin{array}{l}\text { Músculo } \\
\text { Muscle }\end{array}$ \\
\hline & & \multicolumn{5}{|c|}{ 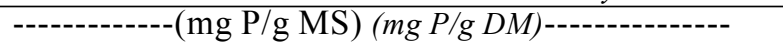 } \\
\hline 0,30 & 94,29 & 66,49 & 11,83 & 6,80 & 11,08 & 5,93 \\
\hline 0,40 & 147,2 & 68,36 & 10,97 & 11,05 & 14,69 & 9,68 \\
\hline 0,51 & 188,3 & 68,61 & 9,79 & 7,52 & 10,35 & 6,02 \\
\hline 0,65 & 256,8 & 74,20 & 12,09 & 10,48 & 12,03 & 7,44 \\
\hline 0,73 & 276,9 & 51,28 & 7,03 & 6,10 & 6,83 & 4,12 \\
\hline Média & 192,70 & $65,79^{\mathrm{a}}$ & $10,34^{b}$ & $8,39^{\mathrm{b}}$ & $10,99^{\mathrm{b}}$ & $6,64^{\mathrm{b}}$ \\
\hline Mean & & & & & & \\
\hline
\end{tabular}

Médias, na linha, seguidas de letras diferentes são diferentes $(P>0,05)$ pelo teste $t$.

Means, within a row, followed by different letters are different $(P<.05)$ by $t$ test. 
vações de UNDERWOOD (1981), MAYNARD et al. (1984), PEO JÚNIOR (1991) e McDOWELL (1992), ao destacarem que os ossos concentram maior proporção do fósforo do organismo animal, podendo atingir níveis entre 75 e $85 \%$ do total.

Com referência ao conteúdo de fósforo em tecidos de mamíferos, visto de forma geral, GEORGIEVSKII (1982) relatou que ocorre grande variação entre os tecidos, destacando que o músculo esquelético apresenta entre 15 e 25 ; os rins, de 10 a 16; o coração, de 15 a 27; e o fígado de 18 a 26 mg/g de tecido, sendo estes dados superiores aos obtidos com os mesmos tecidos dos leitões da presente pesquisa. Os resultados encontrados foram, também, inferiores aos de SMITH et al. (1951), trabalhando com suíno da raça Duroc, com idade e peso similares aos leitões em estudo, que eram de raça diferente.

A taxa de retenção ou de incorporação de ${ }^{32} \mathrm{P}$ no osso, fígado, coração, rim e músculo (Tabela 3 ) não sofreu influência dos níveis de fósforo consumido.
Esta constatação apresentou-se diferente da observada por BUENO (1997), que encontrou efeito linear significativo entre $\mathrm{o}{ }^{32} \mathrm{P}$ retido e o fósforo consumido, em pesquisa com caprinos. Estas divergências podem estar relacionadas com espécie, idade ou fase da criação do animal, intervalo de tempo entre a injeção do ${ }^{32} \mathrm{P}$ e o abate e a coleta de amostras e duração do período experimental, que podem ter interferido no intercâmbio do fósforo das células dos tecidos com o plasma e os fluidos intersticiais. De acordo com SMITH et al. (1951), estes fatores podem reverter tendência de comportamento do fósforo nos tecidos.

$\mathrm{O}$ rim apresentou maior taxa de retenção de ${ }^{32} \mathrm{P}$ que o osso e o fígado $(\mathrm{P}<0,05)$, sendo semelhante aos demais, enquanto o osso teve a menor taxa. $\mathrm{O}$ fígado, o coração e o músculo foram estatisticamente semelhantes entre si.

A baixa retenção de ${ }^{32} \mathrm{P}$ no osso sugere que o período experimental foi insuficiente para ocorrer maior incorporação de fósforo nas células ósseas.

Tabela 3 - Valores do ${ }^{32} \mathrm{P}$ retido nos tecidos em função dos níveis de $\mathrm{P}$ da deita

Table 3 - $\quad{ }^{32} P$ retention in tissues on the dietary total $P$ levels

\begin{tabular}{|c|c|c|c|c|c|c|}
\hline \multirow{3}{*}{$\begin{array}{l}\text { Nível de P total (\%) } \\
\text { Level of total P }\end{array}$} & \multirow{3}{*}{$\begin{array}{c}\text { P consumido } \\
P \text { intake }\end{array}$} & \multirow{2}{*}{\multicolumn{5}{|c|}{$\begin{array}{c}\text { Tipo de tecido } \\
\text { Type of tissue }\end{array}$}} \\
\hline & & & & & & \\
\hline & & $\begin{array}{l}\text { Osso } \\
\text { Bone }\end{array}$ & $\begin{array}{l}\text { Fígado } \\
\text { Liver }\end{array}$ & $\begin{array}{c}\text { Coração } \\
\text { Heart }\end{array}$ & $\begin{array}{c}\operatorname{Rim} \\
\text { Kidney }\end{array}$ & $\begin{array}{l}\text { Músculo } \\
\text { Muscle }\end{array}$ \\
\hline & & \multicolumn{5}{|c|}{ 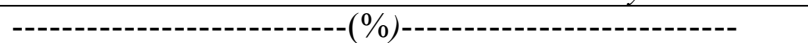 } \\
\hline 0,30 & 94,29 & 0,0152 & 0,0148 & 0,0204 & 0,0207 & 0,0194 \\
\hline 0,40 & 147,2 & 0,0131 & 0,0166 & 0,0141 & 0,0144 & 0,0158 \\
\hline 0,51 & 188,3 & 0,0111 & 0,0164 & 0,0214 & 0,0179 & 0,0160 \\
\hline 0,65 & 256,8 & 0,0097 & 0,0125 & 0,0113 & 0,0151 & 0,0157 \\
\hline 0,73 & 276,9 & 0,0133 & 0,0177 & 0,0207 & 0,0209 & 0,0154 \\
\hline Média & 192,70 & $0,0125^{a}$ & $0,0156^{\mathrm{b}}$ & $0,0176^{\mathrm{bc}}$ & $0,0178^{c}$ & $0,0165^{b c}$ \\
\hline
\end{tabular}

Médias, na linha, seguidas de letras diferentes são diferentes $(P>0,05)$ pelo teste $t$.

Means, within a row, followed by different letters are different $(P<.05)$ by $t$ test.

Tabela 4 - Valores da atividade específica padronizada nos tecidos em função dos níveis de $\mathrm{P}$ total da deita Table 4 - Values of the standard specific activity in tissues on the dietary total $P$ levels

\begin{tabular}{|c|c|c|c|c|c|c|}
\hline \multirow{4}{*}{$\begin{array}{l}\text { Nível de } \mathrm{P} \text { total }(\%) \\
\text { Level of total } P\end{array}$} & \multirow{4}{*}{$\begin{array}{c}\text { P consumido } \\
P \text { intake }\end{array}$} & \multirow{2}{*}{\multicolumn{5}{|c|}{$\begin{array}{l}\text { Tipo de tecido } \\
\text { Type of tissue }\end{array}$}} \\
\hline & & & & & & \\
\hline & & Osso & Fígado & Coração & Rim & Músculo \\
\hline & & Bone & Liver & Heart & Kidney & Muscle \\
\hline$\overline{0,30}$ & 94,3 & 0,2210 & 0,2924 & 0,4095 & 0,4158 & 0,3887 \\
\hline 0,40 & 147,2 & 0,2755 & 0,3478 & 0,2898 & 0,2989 & 0,2894 \\
\hline 0,51 & 188,3 & 0,2452 & 0,3487 & 0,4535 & 0,3816 & 0,3390 \\
\hline 0,65 & 256,8 & 0,2252 & 0,2837 & 0,2609 & 0,3327 & 0,3461 \\
\hline 0,73 & 276,9 & 0,2882 & 0,3858 & 0,4521 & 0,4574 & 0,3337 \\
\hline Média & 192,7 & $0,2510^{\mathrm{a}}$ & $0,3317^{b}$ & $0,3732^{b c}$ & $0,3773^{\mathrm{c}}$ & $0,3394^{b c}$ \\
\hline
\end{tabular}

Médias, na linha, seguidas de letras diferentes são diferentes $(P>0,05)$ pelo teste $t$.

Means, within a row, followed by different letters are different $(P<.05)$ by $t$ test. 
Os resultados estão em consonância com os achados de ABOU-HUSSEIN et al. (1968), LOBÃO e CROCOMO (1974), em estudo com ovinos, e BUENO (1997), com caprinos; porém, divergiram dos de VITTI et al. (1992), também, trabalhando com ovinos, que encontraram maior taxa de incorporação no osso, seguido do fígado, rim e músculo.

Os níveis de fósforo consumidos pelos leitões não influenciaram a atividade específica padronizada nos tecidos (Tabela 4), o que está de acordo com o estudo de VITTI et al. (1992).

A atividade específica padronizada avalia a incorporação do ${ }^{32} \mathrm{P}$ nos tecidos, ou seja, a substituição do do $\mathrm{P}$ estável pelo radioativo, levando em consideração a correção da dose da atividade injetada para o peso dos animais. Nesse contexto, verificou-se que a atividade específica padronizada apresentou o mesmo comportamento do ${ }^{32} \mathrm{P}$ retido nos tecidos. $\mathrm{O}$ maior valor foi encontrado nos rins, que foi semelhante ao do coração e do músculo, e o menor, nos ossos.

SMITH et al. (1951) verificaram que a atividade específica padronizada decresceu nos tecidos de suínos, na ordem: fígado, rim, coração e músculo. O mesmo comportamento foi observado por SMITH et al. (1952) em pesquisa com ovinos, que foi diferente do observado na presente pesquisa: rim, coração, músculo, fígado e osso. Já para BUENO (1997), com caprinos, a ordem foi rim, coração, fígado, músculo e osso, diferindo apenas a posição do fígado e músculo. Na maioria desses trabalhos, no entanto, foi verificada a menor taxa de mobilização no osso e a maior no rim, seguido de coração e fígado, caracterizando-os como locais de maior intercâmbio de fósforo com o plasma e os fluidos intersticiais. A menor taxa verificada nos ossos, provavelmente, está relacionada com o maior conteúdo de fósforo existente neste tecido.

Os valores da atividade específica relativa para osso, fígado coração, rim e músculo (Tabela 5), considerados elevados, revelam a importância destes tecidos no intercâmbio do fósforo existente no interior das células, uma vez que esta variável representa as trocas entre o ${ }^{32} \mathrm{P}$ do plasma com o dos tecidos em estudo.

O músculo, o osso, o fígado e o coração apresentaram valores da atividade específica relativa semelhantes entre si e superiores ao do $\operatorname{rim}(\mathrm{P}<0,05)$, que também foi similar ao do coração. Este comportamento diverge das observações de SMITH et al. (1951), em pesquisa com suínos; VITTI et al. (1992), com ovinos; e BUENO (1997), com caprinos.

As atividades específicas relativas do coração e do músculo não foram influenciadas significativamente pelos níveis de fósforo consumido; no entanto, a do osso (Y) apresentou resposta linear significativa ao fósforo consumido $(\mathrm{X})$, equação $\hat{\mathrm{Y}}=0,4257+0,0011 \mathrm{X}, \mathrm{R}^{2}=$ $0,44, \mathrm{P}<0,05$. Comportamento semelhante foi observado com o fígado e, também, com o rim, segundo as equações de regressão $\hat{\mathrm{Y}}=0,3343+0,0015 \mathrm{X}, \mathrm{R}^{2}=$ 0,$4103 ; \mathrm{P}<0,05$ e $\hat{\mathrm{Y}}=0,3001+0,0011 \mathrm{X}, \mathrm{R}^{2}=0,47$, $\mathrm{P}<0,05$, respectivamente. Esta constatação denota aumento da taxa metabólica neste tecidos com o

Tabela 5 - Valores da atividade específica relativa nos tecidos em função dos níveis de P da deita

Table 5 - Values of the relative specific activity in tissues on the dietary total $P$ levels

\begin{tabular}{lcccccc}
\hline $\begin{array}{l}\text { Nível de P total (\%) } \\
\text { Level of total } P\end{array}$ & $\begin{array}{c}\text { P consumido } \\
\text { P intake }\end{array}$ & \multicolumn{5}{c}{$\begin{array}{c}\text { Tipo de tecido } \\
\text { Type of tissue }\end{array}$} \\
\cline { 3 - 7 } & & Osso & Fígado & Coração & Rim & Músculo \\
Hiver & Heart & Kidney & Muscle \\
\hline 0,30 & 94,3 & 0,5124 & 0,4163 & 0,5087 & 0,4601 & 0,5871 \\
0,40 & 147,2 & 0,5934 & 0,6211 & 0,4368 & 0,3868 & 0,4868 \\
0,51 & 188,3 & 0,6673 & 0,6839 & 0,7501 & 0,5517 & 0,6839 \\
0,65 & 256,8 & 0,5619 & 0,6016 & 0,4968 & 0,5012 & 0,7915 \\
0,73 & 276,9 & 0,8109 & 0,8200 & 0,6667 & 0,7076 & 0,7036 \\
Média & 192,7 & $0,6292^{\mathrm{a}}$ & $0,6286^{\mathrm{a}}$ & $0,5718^{\mathrm{ab}}$ & $0,5215^{\mathrm{b}}$ & $0,6506^{\mathrm{a}}$
\end{tabular}

Mean

Médias, na linha, seguidas de letras diferentes são diferentes $(P>0,05)$ pelo teste $t$.

Means, within a row, followed by different letters are different $(P<.05)$ by $t$ test.

1 Efeito linear $(P<0,05)$

Linear effect $(P<.05)$ 
crescimento da ingestão do fósforo da dieta, o que está de acordo com ANNENKOV (1982), ao afirmar que o fósforo é metabolizado a taxas rápidas no fígado $\mathrm{e}$ rim, porém diverge com relação ao osso, no qual se destaca que o metabolismo é mais lento neste tecido.

Verificou-se que a retenção de ${ }^{32} \mathrm{P}$ e a atividade específica padronizada foram negativamente correlacionadas com a concentração de fósforo nos tecidos. Esta observação sugere que nos tecidos com menor teor de fósforo, como os tecidos moles, o intercâmbio das células (mobilização e captação) com fluidos extracelulares é maior, fazendo com que maior proporção de fósforo estável seja substituído pelo radioisótopo.

\section{Conclusões}

Os níveis de fósforo consumido não influenciaram a concentração de fósforo no osso, fígado, coração, rim e músculo.

A taxa de retenção de ${ }^{32} \mathrm{P}$ decresceu nos tecidos, na seguinte ordem: rim, coração, músculo, fígado e osso, independente da quantidade de fósforo consumido.

As trocas de fósforo entre o plasma e os tecidos, osso, fígado e rim, cresceram com o aumento da ingestão de fósforo da dieta.

\section{Referências Bibliográficas}

ABOU-HUSSEIN, E.R.M., RAAFAT, M.A., EL GINDI, I.M.et al. 1968. Metabolism of ${ }^{32} \mathrm{P}$ in sheep. Pakistan J. Sci. Res.,20(1/2):28-33.

ANNENKOV, B.N. 1982. Kinetics of mineral metabolism in blood. In: GEORGIEVSKII, V.I., ANNENKOV, B.N., SAMOKHIN, V.I. (Eds.) Mineral nutrition of animals. 1.ed. London: Butterworths. p.243-256.

ASSOCIATION OF OFFICIAL ANALYTICAL CHEMISTS AOAC. 1980. Official methods of analysis. 13 ed. Washington: AOAC, $1018 \mathrm{p}$.

BELLAVER, C. (s.d.) Exigências nutricionais de suínos. In: CURSO DE ATUALIZAÇÃO DE NUTRIÇÃO DE SUÍNOS. EMBRAPA. p.1-19.

BUENO, S.M. Niveis de fósforo para caprinos: metabolismo, cinética e digestibilidade aparente. Piracicaba: USP, 1997. 57p. Tese (Doutorado) - Centro de Energia Nuclear na Agricultura, Universidade de São Paulo, 1997.

FISKE, C.H., SUBBAROW, Y. 1925. The colorimetric determination of phosphorus. J. Biol. Chem., 66(2):375-400.

GEORGIEVSKII, V.I. 1982. The physiological role of macroelements. In: GEORGIVIESKII, V.I., ANNENKOV. B.N., SAMOKHIN V.T. (Eds.) Mineral nutrition of animals. 1.ed. London: Butterworths. p.91-170.
INTERNATIONAL ATOMIC ENERGY AGENCY - IAEA. 1979. Laboratory training manual on the use of nuclear techniques in animal research. Vienna: IAEA, 299p. (Technical Report Series, 193).

LOBÃO, A.O., CROCOMO. O.J. 1974. Retenção de fósforo radioativo $\left({ }^{32} \mathrm{P}\right)$ em tecidos de ovinos. Bol. Ind. Anim., 31(2):261-291.

LOFGREEN, G. P. 1960. The availability of the phosphorus in dicalcium phosphate, bone, meal, soft phosphate and calcium phytates for mature wethers. J. Nut.,70(1):58-62.

MAYNARD, L.A., LOOSLI, J.K., HINTZ, H.F. et al. 1984. Nutrição animal. 3. ed. Rio de Janeiro: Livraria Freitas Bastos. 726p.

McDOWELL, L.R. 1992. Mineral in animal and human nutrition. San Diego: Academic Press. 524p.

NASCIMENTO FILHO, V.F., LOBÃO, A.O. 1977. Detecção de P-32 em amostras de origem animal e vegetal por efeito Cerenkov, cintilação líquida e detector GM. Piracicaba: CENA. 25p. (Boletim Científico, 48).

PEKAS, J.C. 1968. Versatile swine laboratory apparatus for physiologic and metabolic studies. J. Anim. Sci., 27(5):1303-1306.

PEO JR., E.R. 1991. Calcium, phosphorus and vitamin D in swine nutrition. In: MILLER, E.R., ULREY, D.E., LEWIS, A.J.(Eds.) Swine nutrition. Boston: Butterworth-Hainemann, p. $165-182$.

ROSTAGNO, H.S., SILVA, D.J., COSTA, P.M.A. et al. 1987. Composição de alimentos e exigências nutricionais de aves e suínos: tabelas brasileiras. Viçosa: Imprensa Universitária. $59 \mathrm{p}$.

SARRUGE, J.R., HAAG, H.P. 1974. Análises químicas em plantas. Piracicaba: ESALQ/USP. 56p.

SMITH, A.H., KLEIBER, M., BLACK, A.L. et al. 1951. Distribuition of intravenously injected radioative phosphorus $\left({ }^{32} \mathrm{P}\right)$ among swine tissue. J. Anim. Sci., 10(4):893-901.

SMITH, A.H., KLEIBER, M., BLACK, A.L. et al. 1952. Distribuition of intravenously injected radioative phosphorus $\left({ }^{32} \mathrm{P}\right)$ among sheep tissue. J. Anim. Sci., 11(4):638-645.

STATISTICAL ANALYSIS SYSTEM. 1986. SAS System for linear models. Cary: SAS Institute. $211 \mathrm{p}$.

UNDERWOOD, E.J. 1981. The mineral nutrition of livestock. 2. ed. London: Commonwealth Agricultural Bureaux. 179p.

VITTI, D.M.S.S., ABDALLA, A.L., MEIRELLES, C.F. 1992. Cinética do fósforo em ovinos suplementados com diferentes fontes fosfatadas através da técnica de diluição isotópica. Arq. Bras. Med. Vet. Zootec., 44(3):227-233.
Recebido em: 14/10/98 Aceito em: 27/01/99 